\title{
PENGARUH SPIRITUAL EMOTIONAL FREEDOM TECHNIQUE TERHADAP INTENSITAS NYERI PADA PASIEN POST SECTIO CAESAREA DI RUMAH SAKIT GRANDMED LUBUK PAKAM TAHUN 2020
}

\section{PITRIANI ${ }^{1}$, DIAN ANGGRI YANTI ${ }^{2}$, SAMUEL GINTING ${ }^{3}$}

\author{
1,2,3 INSTITUT KESEHATAN MEDISTRA LUBUK PAKAM \\ Jl. Sudirman No. 38 Lubuk Pakam Kab. Deli Serdang, \\ Sumatera Utara \\ e-mail: anipitri663@gmail.com
}

DOI : $10.35451 / j k f . v 3 i 1.506$

\begin{abstract}
This study aims to determine the effect of Spiritual Emotional Freedom Technique on Pain Intensity in Post Sectio Caesarea Patients in the Hospital. Grandmed Lubuk Pakam. The benefit of Spiritual Emotional Freedom Technique Therapy is to ensure that the flow of psychological resistance, in the form of spontaneous negative thoughts or negative unconscious beliefs . This study included a qualitative study with One Group pre and Post test design conducted at the Grandmed Lubuk Pakam Type-B Hospital. The study was conducted from January to June 2020 with a population of 160 patients with sectio caesarea and the sample method used was using the method purposive sampling. The data collection technique used is using the Observation Test Statistic Sheet used in this study is Wilcoxon to see there is an independent influence with the Spiritual Emotional Freedom Technique $t$ echnique in post Sectio Caesarea patients. Based on the results of research and analysis used it was found that the majority of respondents aged 23-26 years, Employment Employees with 23 respondents and the last educated junior high school with 14 respondents. There is an influence of Spiritual Emotional Free dom Technique therapy on pain intensity in Caesarean post section patients with a value of $p=<.000<0.05$.
\end{abstract}

Keywords: decreased intensity, pain, SEFT therapy.

\section{PENDAHULUAN}

Sectio Caesarea merupakan prosedur pembedahan untuk mengelu arkan janin melalui insisi di dinding a bdomen (laparatomi)dan dinding ter us atau histerektomi sehingga ibu bayi terkadang merasakan nyeri didaerah luka yang di insisi. Sectio caesarea semakin meningkat kejadiannya seba gai pilihan melahirkan di beberapa ne gara dalam beberapa tahun terakhir (Sihombing, 2017).

Luka yang terdapat di perut pasca sectio secarea yang dirasakan pada ibu mengakibatkan nyeri, Nyeri merupakan suatu pengalaman sensori dan emosi yang terjadi akibat adanya kerusakan jaringan yang actual dan potensial yang mengakibatkan suatu pengalaman yang dialami ibu tidak menyenangkan.Tingkat dan keparaha 
n nyeri pasca operatif terganggu

pada fisiologis nyeri yang timbul pada psikologis individu (Hartati, 2014).

Nyeri pada daerah insisi merupakan suatu komplikasi yang timbul setelah terjadinya tindakan section caesarea, akan terjadi thrombosis, terjadi penurunan kemampuan fungsional, penurunan elastisitas otot perut dan otot dasar panggul, perdarahan, luka kandung kemih, infeksi, bengkak pada eksremitas bawah, dan gangguan laktas. Pasien post Sectio Caesarea akan mengeluh nyeri pada daerah in sisi yang disebabkan oleh robeknya jaringan pada dinding perut dan dind ing uterus .Prosedur pembedahan yang menambah rasa nyeri seperti infeksi, distensi, spasmus otot sekitar daerah. (Zainuddin, 2014).

Menurut World Health Organiz ation (WHO) tahun 2013, standar rata-rata seksio sesar disebuah negara ada sekitar 5-15\% per 1000 kelahiran di dunia,rumah sakit memer intah rata-rata $11 \%$, sementara di rumah sakit swasta biasa lebih dari $30 \%$. Angka kelahiran di Indonesia masih terlalu tinggi dengan perkiraan $15 \%$ dari seluruh wanita hamil meng alami komplikasi pada saat persalinan. Hal seperti ini sangat dibutuhkan tindakan section ceasarea jalan keluar yang untuk mengalami komplikasi pada saat persalinan (Muchtar, 2013).

Pada tahun 2009 untuk angka kejadian seksio secarea di beberapa Negara di Eropa seperti Amerika Serikat untuk jumlah persalinan sebanyak 35\%, Australia dari seluruh persalinan sebanyak $35 \%$ mengalami seksio sesarea ,Skotlandia dari seluru h persalinan sebanyak $43 \%$ meng alami seksio sesarea, Prancis dari seluruh persalinan sebanyak $28 \%$ mengalami seksio sesarea. (Sihombing, 2017).
Hasil Riskesdas tahun 2013 menunjukkan kelahiran dengan meto de operasi Sectio Caesarea sebesar 9,8 persen dari total 49.603 kelahiran sepanjang tahun 2010 sampai deng an 2013, dengan proporsi tertinggi di DKI Jakarta $(19,9 \%)$ dan terendah di Sulawesi Tenggara (3,3\%). Secara umum pola persalinan melalui sectio caesaria menurut karakteristik menun jukkan proporsi tertinggi pada masyar akat yang tinggal di perkotaan $(13,8$ $\%)$, pekerjaan sebagai pegawai $(20,9$ $\%$ dan pendidikan tinggi / lulus PT $(25,1 \%)$.

Terapi Spiritual Emosional Freed om Technique (SEFT)merupakan ter api yang sangat mudah untuk dilakukan dengan menggunakan ketukan ringan (tapping) pada 18 titik kunci di sepanjang 12 energi tubuh , dan efek penyembuhan dapat langsu ng dirasakan secara instan (one min utes wonder).Selain untuk penyembu han baik fisik maupun emosi. Juga dapat digunakan untuk meningkatkan prestasi dan kedamaian hati. Terapi Spiritual Emotional Freedom Techniqu e (SEFT ) menggunakan teknik yang aman, mudah, cepat dan sederhana , bahkan tanpa risiko karena tidak me nggunakan alat atau jarum. Hanya dengan jari telunjuk dan jari tengah kita yang di ketuk-ketukan ringan di beberapa titik meridian tubuh. Selain itu, dengan melibatkan Tuhandalam proses energi psikologi ini menjadikan SEFT mengalami amplifying effect sehingga spektrum masalah yang dapat diatasi juga jauh lebih luas meliputi fisik dan emosi, kesuksesan diri, kebahagiaan hati dan menjadikan jalan menuju personal greatnes (kem uliaan diri) (Zainuddin, 2014).

SEFT merupakan salah satu inovasi teknik konseling , tahapan tekniknya mendayagunakan aspek as mani, psikis, dan spiritual manusia secara harmonis.Ketiga aspek terse 
but digunakan untuk membantu mengatasi permasalahan pasien.

Berdasarkan data awal penelitian yang di dapat dari RS. GrandMed Lubuk Pakam bahwa jumlah pasien Post SC pada bulan januari 2020 yaitu 160 orang sedangkan bulan februari 147 orang, berdasarkan hasil observasi peneliti terhadap pasien Post SC di ruang 2 bahwa 10 orang pasien mengeluh kesakitan di daerah luka insisi, timbulnya rasa nyeri yang masih terasa setelah SC umumnya membuat pasien enggan menggerakkan badannya yang mengganggu kenyamanan pasien.

\section{METODE}

Penelitian ini menggunakan metode Quasy experiment dengan rancangan One Group pre end Post test design yang bertujuan untuk mengetahui perubahan intensitas nyeri sebelum dan sesudah dilakukan (Spiritual Emotional Freedom Technique). Rancangan ini tidak memiliki kelompok pembanding (control)akan tetapi dilakukan observ asi pertama (pretest)yang memungki nkan peneliti menguji perubahan yang terjadi setelah adanya eksperimen (Notoatmodjo, 2013).

\section{HASIL}

Berdasarkan penelitian yang telah dilakukan kepada 45 orang pasien yang menjadi responden diruang rawat inap 2 B (Belakang) Rumah Sakit Grandmed Lubuk Pakam yang telah memenuhi syarat menjadi responden dengan ketentuan yang telah dibuat. Karakteristik responden dalam penelitian ini berdasarkan umur, pekerjaan, pendidikan. Karakteristik responden dapat dilihat dalam bentuk table dibawah ini.

Tabel 3.1 Karakteristik Responden

\begin{tabular}{|c|c|c|c|}
\hline $\begin{array}{l}\text { No } \\
\text {. }\end{array}$ & Umur & $\begin{array}{l}\text { Frekue } \\
\text { nsi (F) }\end{array}$ & $\begin{array}{l}\text { Persen } \\
\text { tase( } \% \\
)\end{array}$ \\
\hline 1 & 18-22 Thn & 11 & 24,4 \\
\hline 2 & 23-26 Thn & 12 & 26,7 \\
\hline 3 & 27-31 Thn & 11 & 24,4 \\
\hline \multirow[t]{2}{*}{4.} & 32-35 Thn & 11 & 24,4 \\
\hline & Jumlah & 45 & 100,0 \\
\hline No & $\begin{array}{l}\text { Pekerjaa } \\
\text { n }\end{array}$ & $\begin{array}{l}\text { Frekue } \\
\text { nsi (F) }\end{array}$ & $\begin{array}{l}\text { Persent } \\
\text { ase } \\
(\%)\end{array}$ \\
\hline 1. & Karyawan & 23 & $51,1^{\prime}$ \\
\hline \multirow[t]{2}{*}{2.} & $\begin{array}{l}\text { Ibu rumah } \\
\text { tangga }\end{array}$ & 22 & 48,9 \\
\hline & Jumlah & 45 & 100,0 \\
\hline No & $\begin{array}{l}\text { Pendidik } \\
\text { an }\end{array}$ & $\begin{array}{l}\text { Frekue } \\
\text { nsi (F) }\end{array}$ & $\begin{array}{l}\text { Persent } \\
\text { ase } \\
(\%)\end{array}$ \\
\hline 1. & SD & 10 & 22,2 \\
\hline 2. & SMP & 14 & 31,1 \\
\hline 3. & SMA & 11 & 24,4 \\
\hline 4. & $\begin{array}{l}\text { Perguruan } \\
\text { Tinggi }\end{array}$ & 10 & 22,2 \\
\hline & Jumlah & 45 & 100,0 \\
\hline $\begin{array}{l}\text { dike } \\
\text { berc } \\
\text { tahi } \\
23- \\
(26 \\
\text { orar } \\
\text { seb } \\
\text { Kar } \\
\text { pek } \\
\text { orar } \\
\text { pek } \\
\text { resp } \\
\text { pen } \\
\text { seb } \\
\text { (31 }\end{array}$ & $\begin{array}{l}\text { Pada tabe } \\
\text { tahui kar } \\
\text { asarkan un } \\
\text { n sebanyał } \\
6 \text { tahun } \\
7), 27-31 \\
9 \quad(24,4 \% \\
\text { inyak } 11 \\
\text { kteristik } \\
\text { erjaan Kar } \\
\text { g respon } \\
\text { erjaan ibu r } \\
\text { onden (4 } \\
\text { didikan may } \\
\text { inyak } 14 \\
\text { 1\%). }\end{array}$ & $\begin{array}{l}3.1 \mathrm{~d} \\
\text { kteristik } \\
\text { ur respo } \\
11 \text { orar } \\
\text { sebanyak } \\
\text { tahun } \mathrm{s} \\
\text {,dan } 32 \\
\text { orang } \\
\text { dekerjaan } \\
\text { awan s€ } \\
\text { den (51 } \\
\text { mah tang } \\
3,9 \% \text { ), } \\
\text { oritas pen } \\
\text { orang }\end{array}$ & $\begin{array}{l}\text { iatas dapat } \\
\text { responden } \\
\text { nden } 18-22 \\
\text { gg(24,4\%) } \\
12 \text { orang } \\
\text { ebanyak } 11 \\
2-35 \text { tahun } \\
(24,4 \%) \text {. } \\
\text { mayoritas } \\
\text { banyak } 23 \\
1 \%) \text { dan } \\
\text { ga } 22 \text { orang } \\
\text { karakteristik } \\
\text { didikan SMP } \\
\text { responden }\end{array}$ \\
\hline
\end{tabular}


Sebelum pemberian terapi Spiritual Emotional Freedom Techniqu e (SEFT).

Tabel 3.2 Karakteristik responden sebelum pemberian terapi Spiritual emotional freedom technique (SEFT)

\begin{tabular}{cccc}
\hline No & $\begin{array}{l}\text { Karakteristik } \\
\text { tingkat } \\
\text { Intensitas } \\
\text { nyeri }\end{array}$ & $\begin{array}{c}\text { Frekue } \\
\text { nsi (f) }\end{array}$ & $\begin{array}{c}\text { Persen } \\
\text { tase } \\
(\%)\end{array}$ \\
\hline $1 . \quad 0 \begin{array}{c}\text { tidak ada } \\
\text { nyeri }\end{array}$ & 0 & 0 \\
2. & $1-3$ nyeri ringan & 1 & 2,2 \\
3. & $\begin{array}{c}4-6 \text { nyeri } \\
\text { sedang }\end{array}$ & 44 & 97,8 \\
4. & $7-10$ nyeri berat & 0 & 0 \\
\hline & Jumlah & 45 & 100,0 \\
\hline
\end{tabular}

Berdasarkan hasil penelitian pada tabel $\quad 3.2$ tentang Pengaruh terapi emotiona freedom technique (SEFT) terhadap tingkat kecemasan pada pasien pre Sectio Caesarea Diruang 2b Rumah Sakit Grandmed Lubuk Pakam Tahun 2020. Berdasarkan sebelum tindakan terapi Spiritual emotional freedom technique diketahui bahwa sebanyak 44 orang responden $(97,8 \%)$ mengalami nyeri sedang, 1 orang responden $(2,2 \%)$ mengalami nyeri ringan, $0 \%$ responden tidak ada nyeri, dan nyeri berat.

Setelah pemberian Terapi Spiritual Emotional Freedom Technique (SEFT).

Tabel 3.3 Karakteristik responden berdasarkan setelah pemberian terapi Spiritual emotional freedom technique (SEFT)

\begin{tabular}{cccc}
\hline No & $\begin{array}{c}\text { arakteristik } \\
\text { intensitas } \\
\text { nyeri }\end{array}$ & $\begin{array}{c}\text { Freku } \\
\text { ensi (f) }\end{array}$ & $\begin{array}{l}\text { Persen } \\
\text { tase } \\
(\%)\end{array}$ \\
\hline $\mathbf{1}$ & $\begin{array}{c}\text { 0 tidak ada } \\
\text { nyeri }\end{array}$ & 0 & 0 \\
\hline
\end{tabular}

\begin{tabular}{cccc}
\hline 2 & $\begin{array}{c}1-3 \text { nyeri } \\
\text { ringan }\end{array}$ & 45 & 100,00 \\
$\mathbf{4}$ & $\begin{array}{c}4-6 \text { nyeri } \\
\text { sedang }\end{array}$ & 0 & 0 \\
& $\begin{array}{c}7-10 \text { nyeri } \\
\text { berat }\end{array}$ & 0 & 0 \\
& Jumlah & 45 & 100,0 \\
\hline
\end{tabular}

Berdasarkan hasil penelitian pada tabel 3.3 tentang Pengaruhterapi Spiritual Emotional Freedom Technique(SEFT) terhadap intensitas nyeri pada pasien Sectio Caesarea Diruang 2B Rumah Sakit Grandmed Lubuk Pakam Tahun 2020. Berdasarkan setelah Tindakan terapi Spiritual Emotional Freedom Technique diketahui bahwa sebanyak 45 orang $(100 \%)$ ada nyeri ringan dan $0 \%$ responden tidak ada nyeri, nyeri sedang dan nyeri berat.

\subsection{Analisa Bivariat}

Tabel 3.4 Distribusi Frekuensi Dan Persentase Pengaruh Spiritual Emotional Freedom

\begin{tabular}{|c|c|c|c|c|c|c|}
\hline $\begin{array}{l}\text { Tind } \\
\text { a } \\
\text { kan } \\
\text { (SEF } \\
\text { T) }\end{array}$ & $\mathbf{N}$ & $\begin{array}{l}\text { Me } \\
\text { an }\end{array}$ & $\begin{array}{l}\text { Std } \\
\text { Dev } \\
\text { iati } \\
\text { on }\end{array}$ & Min & $\begin{array}{l}\mathbf{M} \\
\mathbf{a} \\
\mathbf{x}\end{array}$ & $\begin{array}{l}\text { Nil } \\
\text { ai p }\end{array}$ \\
\hline
\end{tabular}

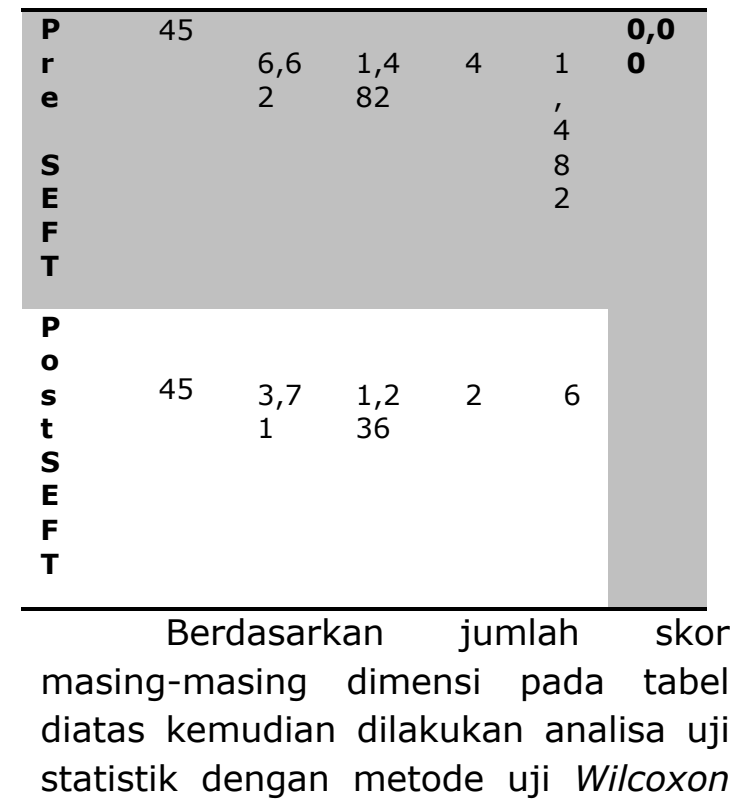


artinya $\mathrm{H}_{1}$ diterima sehingga ada Pengaruh Spiritual emotional freedom technique tingkat nyeri pada pasien Sectio Caesarea Di lantai ruang 2b Rumah Sakit Grandmed Lubuk Pakam tahun 2020. Interprestasi data yang lebih mudah yaitu dengan melihat indeks $P$ Value sebesar $=, 000<(0,05)$. Oleh karena itu dapat ditarik kesimpulan bahwa $\mathrm{H}_{1}$ diterima. Sehingga terdapat Pengaruh Spiritual Emotional Freedom Technique tingkat nyeri pada pasien Sectio Caesarea Diruang 2bRumah Sakit Grandmed Lubuk Pakam Tahun 2020.

\section{PEMBAHASAN}

Berdasarkan umur responden mayoritas pasien operasi section caesarea 23-26 Tahun sebanyak 12 orang responden $(26,7 \%)$ menurut penelitian Hartati 2014, yang pernah dilakukan umur lebih dari 35 tahun lebih rentang melakukan operasi sectio caesarea karena jaringan dan alat-alat kandungan mengalami proses penuaan sehingga rentang terhadap penyakit dimana penyakit dapat mengganggu peredaran darah plasenta. Karakteristik pekerjaan mayoritas pekerjaan karyawan sebanyak 23 orang responden $(51,1 \%)$ dan pekerjaan ibu rumah tangga 22 orang responden $(48,9 \%)$. Ibu yang bersalin sectio caesarea mayoritas yang dialami oleh ibu yang bekerja. Menurut M. Tahir et all 2018, semakin rendah pendapatan semakin rendah pula motivasi ibu untuk memeriksa kehamilan dan ibu kurang memanfaatkan pelayanan kesehatan yang ada (Notoadmodjo, 2013).

\section{Karakteristik} pendidikan mayoritas pendidikan SMP sebanyak 14 orang responden $(31,1 \%)$. Dalam penelitian Wijayanti 2012, menyatakan bahwa, pada pasien yang mempunyai pendidikan lebih tinggi akan mempunyai pengetahuan yang lebih luas tentang bagaimana mengatasi nyeri yang dia derita, mempunyai rasa percaya diri serta dapat mengurangi kecemasan sehingga dapat membantu individu tersebut dalam membuat keputusan (Notoadmodjo, 2013).

Nyeri pasien sebelum diberikan perlakukan intensitas nyeri sedang ada 44 orang $(97,8 \%)$. Karena nyeri sebelum diberikan perlakuan pada pasien post sectio caesarea lebih besar sehingga menjadi masalah keperawatan yang utama. Sesuai dengan asumsi peneliti bahwa Nyeri post operasi akan meningkatkan stress post operasi dan memiliki pengaruh negatif pada penyembuhan.

Pasien dengan perlakuan SEFT (Spiritual Emotional Freedom Technique) dengan mengurangi intensitas nyeri terhadap pasien post sectio caesarea intensitas ringan ada 45 orang $(100 \%)$. Dari jumlah sampel sebanyak 45 orang. Diketahui dengan lembar observasi yang dilakukan intensitas nyeri pada pasien post sectio caesarea lebih kecil sesudah dilakukan teknik SEFT (Spiritual Emotional Freedom Technique) pada pasien post sectio caesarea.

Asumsi peneliti bahwa dengan sudah dilakukannya tindakan SEFT membuat pasien merasa tenang, nyaman, dan rileks yang dapat mengurangi nyeri. Untuk Pengaruh Spiritual Emotional Freedom Technique terhadap intensitas nyeri pada pasien post sectio caesarea dirumah sakit Grandmedistra Lubuk Pakam tahun 2020.

Diketahui bahwa hasil analisa uji statistik dengan metode uji Wilcoxon artinya $\mathrm{H}_{1}$ diterima sehingga ada Pengaruh Spiritual emotional freedom technique tingkat nyeri pada pasien Sectio Caesarea. 


\section{KESIMPULAN}

Hasil dari penelitian dapat disimpulkan bahwa karakteristik responden terbanyak berdasarkan umur responden 23-26 tahun sebanyak 12 orang $(26,7)$, Karakteristik pekerjaan mayoritas pekerjaan Karyawan sebanyak 23 orang responden $(51,1 \%)$ dan pekerjaan, serta karakteristik pendidikan mayoritas pendidikan SMP sebanyak 14 orang responden $(31,1 \%)$.

Untuk Analisis Bivariat didapat hasil berdasarkan uji Wilcoxon terdapat perbedaan yang signifikan Antara sebelum dan sesudah, dengan hasil Nilai sebelum dilakukan terapi Spiritual emotional freedom technique meliputi nilai mean 6,62 , nilai standar deviation adalah 1,482 , nilai minimum adalah 4 , nilai maximum 1,482 , dan nilai sesudah dilakukan terapi emotional freedom technique meliputi: nilai mean adalah 3,71 , nilai standar deviation adalah 1,236 , nilai minimum adalah 2, nilai maximum 6 dengan hasil indeks $\mathrm{P}$ Value sebesar $=$ , $000<(0,05)$. Oleh karena itu dapat ditarik kesimpulan bahwa Ho di tolak. Sehingga terdapat Pengaruh Spiritual emotional freedom technique terhadap tingkat nyeri pada pasien sectio caesrea di Rumah Sakit Grandmed Lubuk Pakam.

\section{DAFTAR PUSTAKA}

Hartati, S (2014) Faktor-Faktor Yang Mempengaruhi Ibu Post Partum Pasca Seksio Cesaria. Untuk Melakukan Mobilisasi Dini di RSCM. Jurnal Keperawatan

Riskesdas. (2013). Riset Kesehatan Dasar; RISKESDAS. Jakarta: Balitbang Kemenkes Ri.

Manuaba, IDA. 2015. Ilmu Kebidanan. Penyakit Kandungan dan Keluarga Berencana. Jakarta: EGC.
Maryunani, A (2015) Asuhan Keperawatan Ibu Post partum Seksio Sesarea Cetakan Pertama. Jakarta Timur

MUchtar, (2013). Sinopsis Obstetri Jilid 1. Jakarta : EGC.

Notoatmodjo,S. 2013. Metodologi Penelitian Kesehatan. Jakarta: Rineka Cipta.

Prasetyo, S.N. (2010). Konsep Dan Proses Keperawatan Nyeri. Yogyakarta: Graha Ilmu.

Sihombing, N 2017 Determinan Persalinan Sektio Caesarea di Indonesia. Jurnal Kesehatan Reproduksi

Sugiyono. 2013. Metode Penelitian Kuantitatif Kualitatif dan R\&D. Bandung.

Tahir, M. et all. (2018). Faktor- Faktor yang berhubungan dengan motivasi ibu hamil untuk memeriksakan kehamilan. Volume 7 Nomor 1 Bulan Juli Tahun 2018 ISSN:2089-9394.

Wijiyanti, Fajar (2010) Efektifitas Terapi Spiritual Emotional Freedom Technique (SEFT) terhadap Penurunan Intensitas Nyeri pada Pasien Paskaoperasi Sectio Caesaria.Undergraduate thesis, Universitas Diponegoro

Zainuddin, Faiz. 2014. Spiritual Emotional Freedom Technique For Healing, Succes, Happiness, Greatness. Edisi Revisi, Jakarta: Afzan Publishing. 